\title{
Bukit Timah Nature Reserve: a forest in transition
}

\author{
K. Chatterjea \\ National Insitute of Education, \\ 1 Nanyang Walk, 637616 Singapore \\ Kalyani.c@nie.edu.sg
}

\begin{abstract}
Bukit Timah Nature Reserve (BTNR), being virtually the only primary rain forest in Singapore, is of very high environmental importance. The forest is located amidst a highly developed residential area and is visited by large numbers of people who seek respite from urban stresses and are invigorated by the natural environment offered by the forest interiors. Trails within the forest are heavily frequented and are, therefore, under constant stress. Results of heavy usage are seen in extreme surface compaction and slope deterioration, which in turn affect the forest bio-physical environment. This paper covers research spanning over 13 years from 2004 ('before forest closure') to 2017 ('after forest reopening'), tracks the degeneration of the forest under such severe patronage by visitors, and reports on changes in the Nature Reserve's physical conditions during and after a period of closure for renovation of public facilities. Several factors of importance to the forest bio-physical environment, such as soil compaction, soil bulk density, soil surface organic matter status, and infiltration rates of surface soils were monitored during these 13 years and visible and measurable longitudinal changes are recorded. Significant improvements are seen in soil compaction values, organic matter content, and bulk density of the trail surface soils subsequent to the forest closure, indicating that the closure and the resultant natural regeneration of the forest has significantly improved the forest interior bio-physical environment. The success of this management strategy can be taken as evidence of good management procedure and can, therefore, set an example to follow in future to sustain the bio-physical status of Bukit Timah Nature Reserve.
\end{abstract}

Keywords: Trail degradation, forest regeneration, forest trail management, trail degradation hazard

\section{Introduction}

Bukit Timah Nature Reserve (BTNR), situated in the centre of the main island of Singapore, is the nation's flagship rain forest reserve, managed by the National Parks Board, Singapore. Considerable parts of this forest still retain the original primary rain forest characteristics and it may be considered one of the prominent remnant natural areas in the heart of a very urbanised part of Singapore island. Being barely 11-12 $\mathrm{km}$ away from the Central Business District of the city and located in the middle of a densely developed residential area, BTNR faces challenges of colossal proportions for its survival and sustainability. The forest has travelled from anonymity to fame and then from degeneration through over-popularity to a carefully-curated revival during the period from the independence of Singapore until the present. This paper relates how the forest environment had gradually deteriorated through over-use in the 
post 1990s when the neighbouring area was designated as the condominium belt of Singapore and how, through active timely intervention by the National Parks Board with some participation from interested nature professionals, the forest has rebounded and is, most likely, on the way to recovery, mostly through natural regeneration.

This paper aims to assess the physical environment within the forest, particularly the forest surface conditions, which, in turn, have immense influence on how the forest vegetative growth performs. The collection of data is intended to assess forest surface conditions, with special emphasis on soil textural characteristics, soil organic status, soil bulk density, soil surface resistance (showing surface compaction) and soil infiltration capacity, to compare the trail surface data with the controlled data from undisturbed and unimpacted forest slopes. The analysis aims to find out the differences in the surface conditions on the impacted surfaces. This, in turn, is expected to reveal the extent to which the trail surfaces were revived from the original severely impacted conditions during two decades of high usage, starting from the 1990s. The choice of research parameters aims to assess the surface conditions on the forest trails during the temporary closure when the forest interior had some time to regenerate itself, and also after reopening. This helps to assess if the forest conditions improved during a period of temporary closure and how the reopened forest is responding to visitors after the trail amelioration work was done.

The appraisal of physical conditions sets the context for all of the biological groups surveyed during the comprehensive biodiversity survey of BTNR that was introduced by Chan \& Davison (2019).

\section{Patterns and impacts of visitor use}

\section{Status of the forest: from unknown to well-known}

The area around BTNR was designated by city planners as a condominium belt and as such, gave way to many high-rise residential developments, starting from 1990 . Chatterjea (2012) discussed how proximity to this patch of forest within $2 \mathrm{~km}$ of the residence of more than 6000 households escalated the visitorship to this forest to a staggering number of more than 1000 people per day (Chatterjea, 2012, 2014a). The 163 ha forest, including some 75 ha of primary forest, along with the criss-crossing trails, were exposed to immense degrees of surface compaction, trail widening, and slope disturbance, all as a result of the high usage by people frequenting the forest (Chatterjea, 2015). Analysis of the visitorship to the forest in the 1990s and 2000s revealed the visiting habits of the people frequenting the forest (Table 1).

From Table 1, it is clear that most people stay in the forest for a short period of about two hours, use the forest as an exercise ground within a natural environment, and prefer the forest trails for their use. The result of these choices by visitors has generally been disruptive for the wellbeing of the trails.

The 2006 survey (Chatterjea, 2006) revealed that, on average, there are $>86$ persons at any one time, trampling on each kilometre of the trails for around two hours and that is alarmingly high. Longitudinal data also revealed that the choices of the 
Table 1. Results of surveys on visitor profiles, preferences, and forest visit trends in Bukit Timah Nature Reserve, Singapore.

\begin{tabular}{lcccl}
\hline N=980 & 2004* & 2006* & 2017 & Comments \\
\hline $\begin{array}{l}\text { People visiting more than } \\
10 \text { times in a year }\end{array}$ & $31 \%$ & $64 \%$ & $65 \%$ & $\begin{array}{l}\text { Popularity of BTNR has increased and is } \\
\text { sustained }\end{array}$ \\
$\begin{array}{l}\text { Length of stay ( }>2 \text { hours) } \\
\text { Length of stay (1-2 hours) }\end{array}$ & $83 \%$ & $84 \%$ & $80 \%$ & \\
$\begin{array}{l}\text { Preferences (Trails) } \\
\text { Objectives of the visit: }\end{array}$ & $76 \%$ & $83 \%$ & $95 \%$ & More people prefer to go to trails \\
$\begin{array}{l}\text { Exercise } \\
\text { Objectives of the visit: }\end{array}$ & $81 \%$ & $89 \%$ & $80 \%$ & Exercise remains a major objective \\
Nature Watch, Relaxing & $19 \%$ & $11 \%$ & $20 \%$ & More people are visiting the forest for \\
\end{tabular}

*The 2004 and 2006 data are collated from Oei et al (2007), Chatterjea (2007), and Chatterjea (2012) and 2017 data were collected after the reopening of the forest.

visitors have changed over the years and now an increasing number of people $(95 \%$ of visitors) are keener to go to the more arduous forest paths than to the metalled main road that leads to the summit. Such high usage, particularly on the forest trails, changed the way Bukit Timah Forest was perceived by the visiting crowds. Revealing details relating to altered usage of the forest come from Chatterjea (2012). Data show that more than $80-89 \%$ of the visitors visit the forest for exercise, trail walking, jogging, and biking, with only $11-20 \%$ of the visitors engaging in nature and bird watching. It is quite obvious that over the years, with its new-found popularity, BTNR has lost its past atmosphere as a secluded environment where people found bird watching and nature watching more engaging, particularly during the morning and early evening peak visiting hours. The crowd thins out after $10 \mathrm{am}$ in the morning before peaking again around $4 \mathrm{pm}$ for another two hours. Research shows that visitor numbers are high during these two periods, when car parks are full, and there are many people along the trails and the main road. While this increase in visitor numbers has repercussions on the wildlife in the forest, this research looks at the physical changes that result from high traffic on the forest trails.

\section{Tracking the altered physical conditions in the impacted forest}

Heavy and continuous human traffic on the unpaved, soil-covered trails increase the surface degradation by compaction of the top surface layers of the soil, rendering them almost impermeable in times of rain. This leads to generation of fast flowing surface wash during the frequent rains. The usual forest cover inhibits generation of surface-wash (Chatterjea, 1989, 1994). But trail surfaces that are compacted from 
heavy usage work like ephemeral streams during heavy rainfall, channelling the surface water along narrow grooves and initiating severe washing out of the top organic layer of the soil profile. Evidence is presented below showing cases where the top soil cover is totally removed through this action of water on disturbed trail slopes.

Field measurements showed that on trail segments where flowing surface water was not present, the organic matter percentage in the top soil was much higher than on trails where surface water had flowed during rain. The surface flow during heavy rains washed out the fragile organic layers, thus reducing the organic matter concentration in the top soils of impacted areas. The impact of heavy usage includes changes in the trail surface conditions, widening of the trails, extension of off-trail sections into the trail segments, grooving of trail surface, water-logging on badly compacted segments which leads to loss of soil consistency and stability, and most importantly, severe trail surface compaction. All of these effects have been observed, measured, and analyzed in detail and the results have been published in a number of articles (Chatterjea, 2007, 2012, 2014b). The final result, as shown in Chatterjea (2007), is a network of trails that are degraded and extended. The compaction on the surface is usually too high for subsequent root penetration and root extension, leading to general degeneration of forest vegetation, particularly along and around the trails.

Since that earlier investigation the forest was closed to visitors for a period. During this closure, when trails were being repaired and realigned, there was no visitor traffic for about two years from 15 September 2014 to 22 October 2016. During this period, with no human traffic impacting on the trails, it was hoped that the trails would recover partially from the earlier heavy impact. This study set out to track the surface condition changes during this closure and compare them to the past data in order to assess the effects of the closure. One set of data was collected during January 2016, when the forest was still totally closed to the public. A subsequent set of data was again collected in early February/March 2017, a few months after the trails were re-opened to the public. This during- and post-closure data is analysed against the backdrop of earlier trail surface conditions during a period of heavy usage between 2004 and 2015.

The report here analyses the longitudinal changes of the trail surface conditions to assess the impact of the closure and how the forest responded to a period of noimpact. The longitudinal analysis of the trail conditions was done for three main factors that impact the trail surface conditions and function as biogeographical indicators of the forest environmental conditions. The factors monitored over this period of 13 years are trail surface compaction, trail surface soil dry bulk density, and trail surface soil organic matter content.

The reason for choosing these specific factors for comparison and monitoring is that earlier studies in this forest (Chatterjea, 2007) revealed that the main impact of excessive usage by visitor traffic is a considerable increase in surface compaction due to impact, which in turn changes the dry bulk density of the soil, reduces infiltration rates, and helps generate very fast flowing surface-wash during heavy downpours. Such uncharacteristic excessive surface-wash erodes trail surface materials, removes productive top soil and organic matter, and exposes the lower soil layers and rocks. 


\section{Physical conditions in the impacted forest: before forest closure}

\section{Trail surface compaction: Soil Penetration Resistance ( $\mathrm{kPa}$ )}

A summary of observations regarding the degeneration of trails between 2004 and 2012 is given in Table 2.

All trails showed severe surface compaction, with Seraya Loop and Dairy Farm Loop leading with extreme degrees of compaction. The degree of compaction increased yearly, as evidenced in Table 2, and maximum surface penetration resistance was recorded in the range of $>2000 \mathrm{kPa}$ to as high as $>4000 \mathrm{kPa}$. Research shows that soil penetration resistance higher than $2000 \mathrm{kPa}$ is detrimental to root development (Bengough \& Mullins, 1991; Sinnett et al., 2008; Moraes et al., 2014). The vast majority of roots were recorded in soils with a penetration resistance of less than 3000 $\mathrm{kPa}(90.7 \%)$ with a significant amount in the less than $2000 \mathrm{kPa}$ class $(70.2 \%)$ (Sinnett et al., 2008).

The worst affected trails were Seraya Loop and Dairy Farm Loop and the trail surfaces were severely pitted, holed, and damaged. Figures 1, 2, and 3 show the increase in surface compaction on Seraya Loop, Dairy Farm Loop, and the rest of the trails, such as Cave Path, Catchment Path, Taban Loop, Southview Path, and Northview Path between 2004 and 2012, when all locations along the trails had deteriorated surface conditions. Dairy Farm Loop had more than $85 \%$ of the locations deteriorated to extreme compact conditions between 2005 and 2012. During this period parts of the two trails expanded sideways with maximum width reaching $5 \mathrm{~m}$ along Seraya Loop, five times the original width of the trails, and steps were created by users on slippery surfaces (Fig. 4A \& B).

Overall, all trail surfaces in BTNR degraded progressively between 2004 and 2012 , in spite of the continuous ad-hoc trail repairs. Records show that out of 78 monitored locations on the trails, $90 \%$ of sites were classified in the moderate to high hazard categories and the trails had become dangerous for use, while also being damaging to the forest environment. Table 3 below shows these changes from 2004 to 2012 .

Figure 5 shows how the degrees of hazard gradually increased over the years. This was a result of excessive human trampling on trails, particularly those on steep slopes, such as Dairy Farm Loop, and Seraya Loop.

Based on measured compaction data, maps were drawn up to demarcate hazardous locations on each trail and this was published in Chatterjea (2007), which could be used as a guide to carry out trail repairs.

Demarcation of hazardous trail segments was done for both forest sustainability as well as visitor safety (Fig. 6). Trails such as Seraya Loop and Dairy Farm Loop were demarcated as being in critical condition. This hazard map clearly shows the areas of concern and all the very critical locations coincided with steep slopes, indicating that compaction on steep slope segments made the surfaces more vulnerable as fast surface wash on steep slopes could do more damage to the top soil by washing them off during severe rains. 
Table 2. Surface compaction between 2004 and 2012 on three trails in Bukit Timah Nature Reserve, Singapore.

\begin{tabular}{|c|c|c|c|c|c|c|c|c|c|c|c|}
\hline \multicolumn{4}{|c|}{ Seraya Loop } & \multicolumn{4}{|c|}{ Dairy Farm Loop } & \multicolumn{4}{|c|}{$\begin{array}{l}\text { Cave, Catchment, Taban, } \\
\text { Southview, Northview }\end{array}$} \\
\hline \multicolumn{2}{|c|}{ Grid Locations } & \multirow{2}{*}{$\begin{array}{c}2004 \\
1323.7\end{array}$} & \multirow{2}{*}{$\begin{array}{l}2005 \\
2758\end{array}$} & \multicolumn{2}{|c|}{$\begin{array}{c}\text { Grid } \\
\text { Locations }\end{array}$} & \multirow{2}{*}{$\begin{array}{l}2005 \\
2413\end{array}$} & \multirow{2}{*}{$\begin{array}{c}2012 \\
3447.4\end{array}$} & \multicolumn{2}{|c|}{$\begin{array}{c}\text { Grid } \\
\text { Locations }\end{array}$} & \multirow{2}{*}{$\begin{array}{c}2005 \\
1724\end{array}$} & \multirow{2}{*}{$\begin{array}{c}2012 \\
3102.6\end{array}$} \\
\hline $\mathrm{C} 194$ & $\mathrm{R} 250$ & & & C195 & $\mathrm{R} 250$ & & & $\mathrm{C} 203$ & R245 & & \\
\hline C193 & $\mathrm{R} 250$ & 1116.8 & 2758 & C196 & $\mathrm{R} 245$ & 827.4 & 2757.9 & $\mathrm{C} 201$ & R243 & 2068 & 2413.2 \\
\hline $\mathrm{C} 193$ & $\mathrm{R} 250$ & 1448.0 & 1724 & C196 & R245 & 1999.5 & 1723.7 & $\mathrm{C} 201$ & R242 & 689.5 & 2068.4 \\
\hline C193 & R249 & 1034.1 & 1379 & C196 & R246 & 1379.0 & 4481.6 & C197 & R237 & 1034.2 & 2413.2 \\
\hline $\mathrm{C} 193$ & $\mathrm{R} 249$ & 1447.7 & 3103 & C196 & R246 & 2344.2 & 3102.6 & $\mathrm{C} 195$ & R245 & 2275 & \\
\hline $\mathrm{C} 192$ & $\mathrm{R} 248$ & 792.8 & 3585 & C196 & R247 & 2344.2 & 2413.2 & $\mathrm{C} 195$ & R246 & 1724 & \\
\hline $\mathrm{C} 192$ & $\mathrm{R} 248$ & 2344.0 & 2068 & C196 & R248 & 1551.3 & 2068.4 & $\mathrm{C} 195$ & R246 & 1379 & \\
\hline $\mathrm{C} 192$ & $\mathrm{R} 247$ & 810.0 & 1034 & C196 & R248 & 1792.6 & 1206.6 & C194 & R247 & 2413 & \\
\hline $\mathrm{C} 192$ & $\mathrm{R} 247$ & 2171.6 & 3103 & C196 & R249 & 689.5 & 1034.2 & C194 & R248 & 2206 & \\
\hline C193 & R247 & & 2206 & C196 & R250 & 1034.2 & 2068.4 & C194 & R248 & 4137 & \\
\hline C193 & $\mathrm{R} 247$ & & 3447 & C196 & R251 & 689.5 & 2413.2 & C194 & R249 & 1655 & \\
\hline \multirow[t]{10}{*}{ C194 } & R247 & & 3103 & C196 & $\mathrm{R} 251$ & 689.5 & 1379.0 & & & & \\
\hline & & & & C196 & R252 & 1310.0 & 1723.7 & & & & \\
\hline & & & & C196 & R252 & 1723.7 & 3792.1 & & & & \\
\hline & & & & C196 & R253 & 1103.2 & 1551.3 & & & & \\
\hline & & & & C195 & R252 & 2206.3 & 1379.0 & & & & \\
\hline & & & & C195 & R251 & 1723.7 & 2240.8 & & & & \\
\hline & & & & C195 & R251 & 2551.1 & 3275.0 & & & & \\
\hline & & & & C195 & $\mathrm{R} 251$ & 1516.9 & 1723.7 & & & & \\
\hline & & & & C195 & $\mathrm{R} 250$ & 1241.1 & 2757.9 & & & & \\
\hline & & & & C195 & $\mathrm{R} 250$ & 1241.1 & 2757.9 & & & & \\
\hline
\end{tabular}

\section{Dry Bulk Density of top soil surface}

High dry bulk density (DBD) is an indicator of low soil porosity and soil compaction. It may cause restrictions to root growth and hinders movement of air and water through the soil. One important effect of this may be to limit a plant's ability to find water. The ability of the plants to access soil water may be limited by the inability of roots to expand throughout the matrix of very compacted, heavy soil. Both root quantity and root distribution help a plant to find and utilise heterogeneously distributed resources in the soil. Deep roots allow access to water unavailable to plants with shorter root systems. The root biomass per unit of soil volume has been noted to increase in nutrient-rich areas (Aanderud et al., 2003). Thus, soil bulk density plays an important role in ensuring that both water and nutrients are readily available to the plants through a well-laid out root system. Characteristically forest soils are light and have high root 


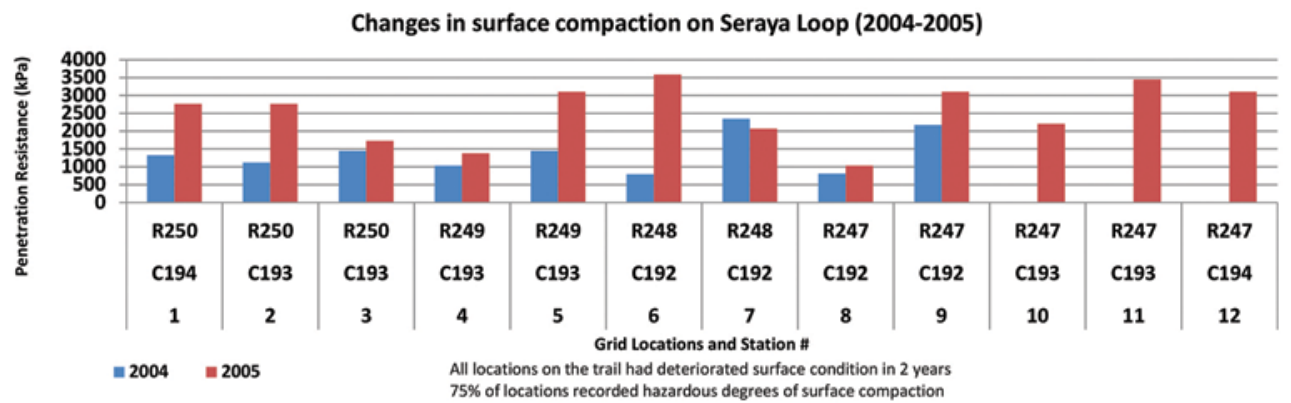

Fig. 1. Changes in surface compaction on Seraya Loop between 2004 and 2005.

Change in Surface compaction on Dairy Farm Loop (2005 - 2012)

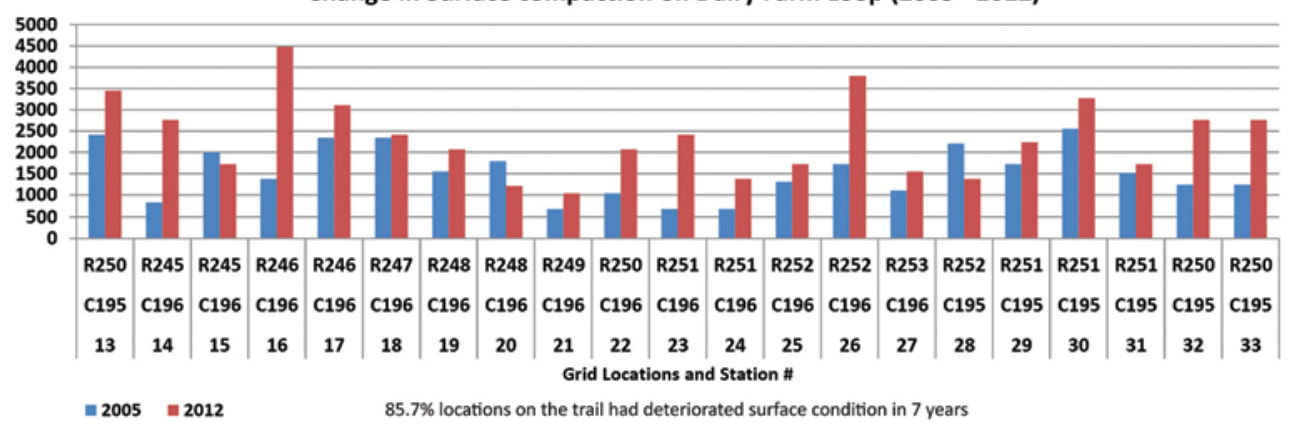

Fig. 2. Changes in surface compaction on Dairy Farm Loop between 2005 and 2012.

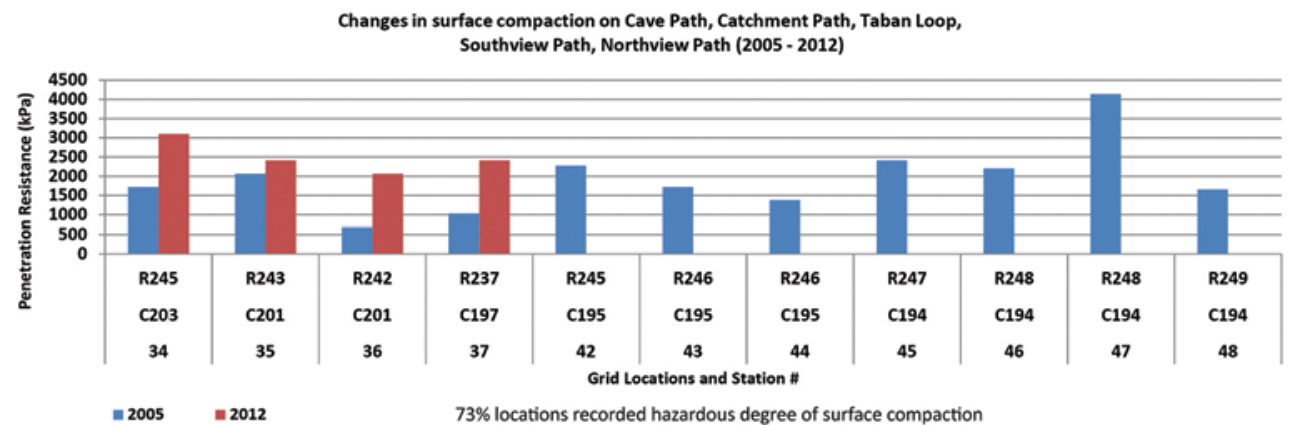

Fig. 3. Changes in surface compaction on rest of the trails between 2005 and 2012.

densities. But on impacted trails the surface has extremely high compaction values, making the surface impenetrable and heavy. Measurements of surface dry bulk densities were carried out on 17 locations along all trails and again the data shows that Seraya Loop and Dairy Farm Loop have the highest values of DBD, with other trails also showing close values. All stations showed DBD higher than $1 \mathrm{~g} / \mathrm{cm}^{3}$, with high 

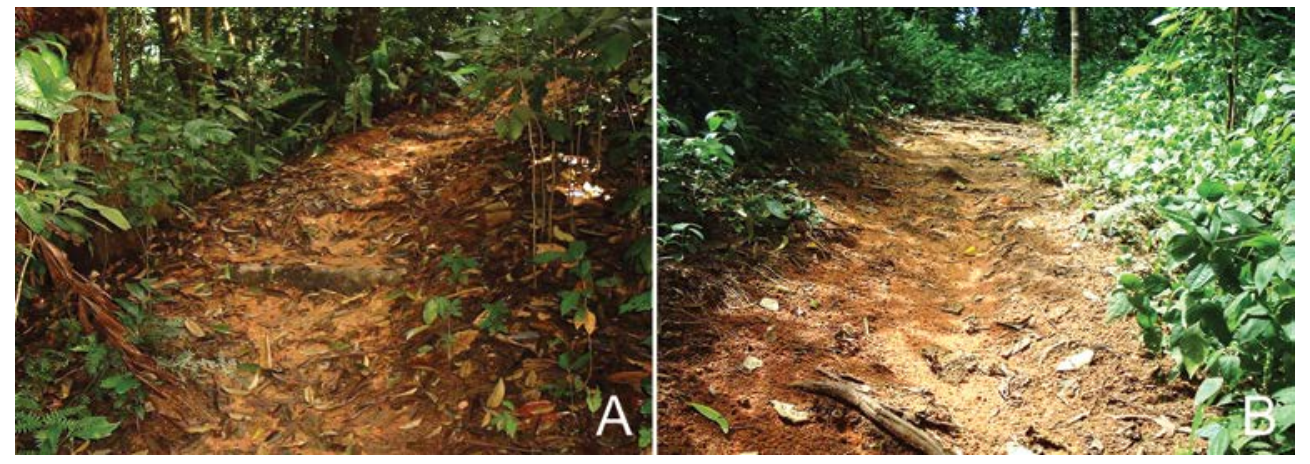

Fig. 4. A \& B. Compacted and widened trails at various locations in Bukit Timah Nature Reserve.

Table 3. Percentage of trail locations under each hazard category between 2004 and 2012 in Bukit Timah Nature Reserve, Singapore.

\begin{tabular}{|c|c|c|c|c|}
\hline$N=78$ & $\begin{array}{l}\text { No Hazard } \\
(<1000 \mathrm{kPa}) \\
\text { (\% of locations) }\end{array}$ & $\begin{array}{l}\text { Low Hazard (1000 } \\
\text { - } 1499 \mathrm{kPa}) \\
\text { (\% of locations) }\end{array}$ & $\begin{array}{l}\text { Moderate Hazard } \\
(1500-1999 \mathrm{kPa}) \\
\text { (\% of locations) }\end{array}$ & $\begin{array}{l}\text { High Hazard } \\
\text { (>2000 kPa) } \\
\text { (\% of locations) }\end{array}$ \\
\hline 2004 & 22.2 & 55.56 & 0 & 22.22 \\
\hline 2005 & 11.36 & 22.72 & 22.72 & 43.18 \\
\hline 2012 & 0 & 16 & 16 & 68 \\
\hline
\end{tabular}

values going up as much as $1.59 \mathrm{~g} / \mathrm{cm}^{3}$. In comparison, data from 32 undisturbed forest locations returned an average value of $0.740 \mathrm{~g} / \mathrm{cm}^{3}$, with the lowest value being $0.224 \mathrm{~g} /$ $\mathrm{cm}^{3}$. Figure 7 shows the distribution of DBD in different locations of BTNR. It is significant that the locations of high DBD are similar to the locations for high surface resistance and these are the worst affected locations on the trails, e.g., C194/R249 on Seraya Loop and C196/R247 on Dairy Farm Loop.

Table 4 shows an important aspect regarding soil bulk densities in the forest. On trails, the soil DBD increased rapidly (almost doubled) immediately below the surface, while under undisturbed forest cover the increase in DBD was more gradual, as well as, much lower in absolute terms. While DBD usually increases downwards with depth on all soils due to the weight of the over-burden, the sharp increase at just $10-20 \mathrm{~cm}$ depth on trails is indicative of external impact, such as from excessive trampling on the trail surface. This can create a cap effect, hindering root penetration and extension in this part of the soil profile. 


\section{Percentage of Trail locations under various hazard classes of surface} compaction (2004 -2012)

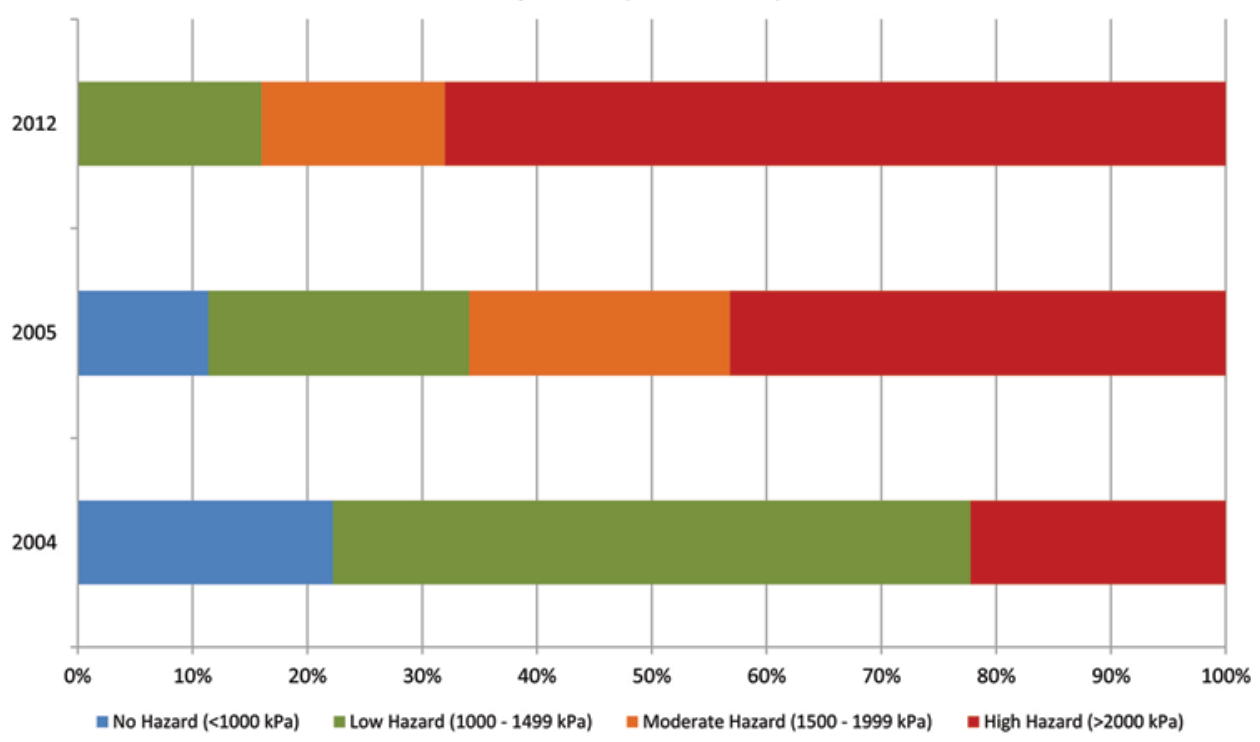

Fig. 5. Gradual degradation of trail surfaces and increase of the hazard scales between 2004 and 2012.

\section{Trail and forest infiltration rates}

With such high compaction of the top soil surface, it is not surprising that infiltration of rainwater to the soil was impeded. Measurements of infiltration rates were carried out on several trails over a few years and generally while the forested slopes allowed ready infiltration, trail surfaces were totally impermeable (Fig. 8).

There was evidence of quick generation of surface wash during rains and heavy concentrations of suspended sediments were recorded in the flowing runoff. Chatterjea $(1989,1994)$ recorded suspended sediment concentrations ranging from 1714 to 5200 $\mathrm{mg} / \mathrm{l}$ on disturbed trails with unimpeded surface runoff, while the forest streams in BTNR recorded only 172 to $222 \mathrm{mg} / 1$ for the same storm event. Generation of surface wash results in removal of the top soil from trail surfaces. This is significant as the top $5-10 \mathrm{~cm}$ of the forest surface holds much of the soil organisms and nutrients.

\section{Trail and Forest Organic matter percentage}

With heavy impact on the trail surfaces and severe surface compaction, the soil cover becomes less permeable to air and water. This inhibits organic activity in the top soil layers. Root densities are also reduced as the compacted soil makes it difficult for root extension. The overall effect of this is a general reduction in the total soil organic matter content. Investigations on the same revealed that the trail surfaces consistently yielded lower organic matter content than the forested slope soils, as seen in Fig. 9. 


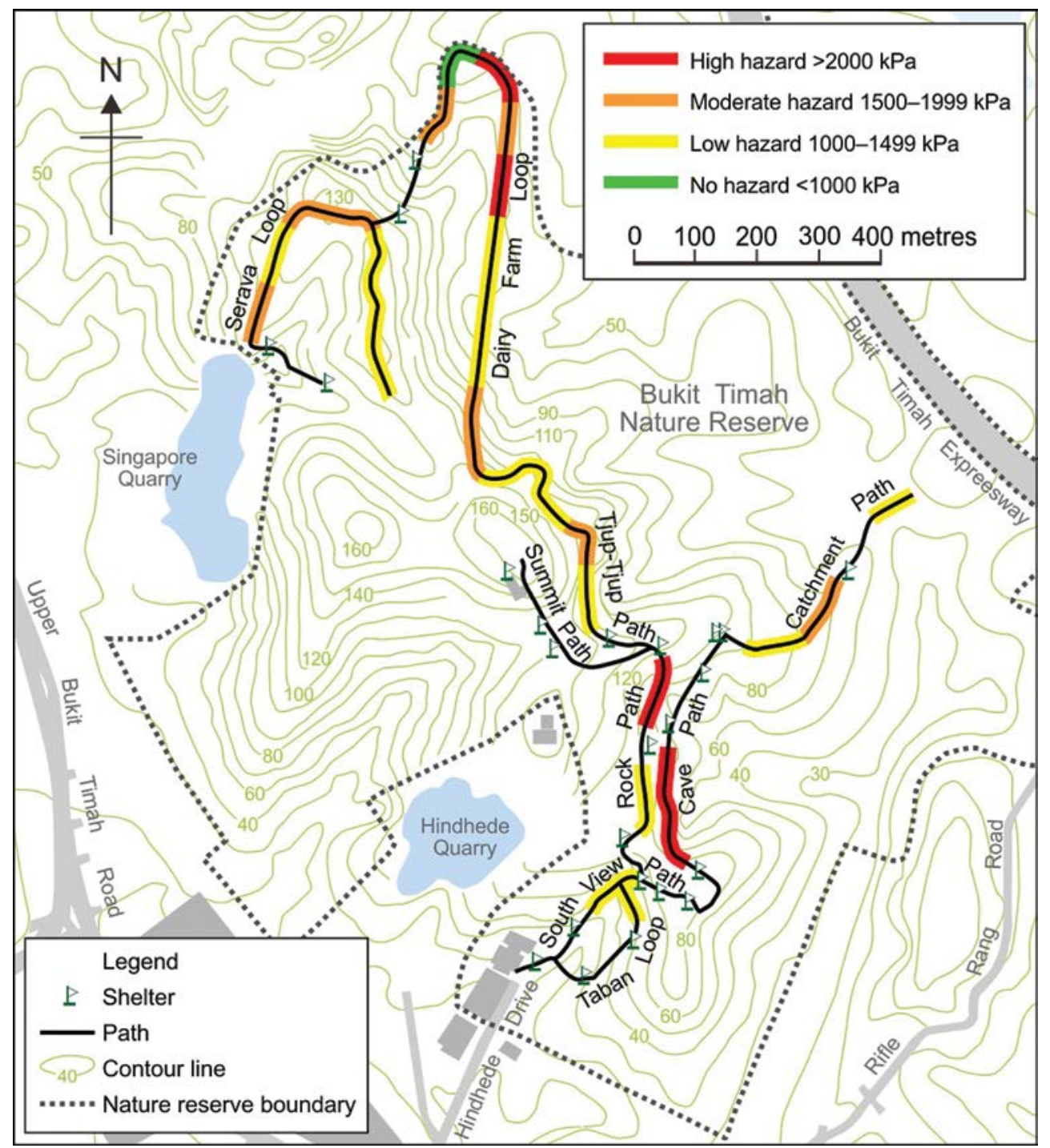

Fig. 6. Trails with their associated Hazard classes, based on surface compaction data.

Field measurements of dry root mass percentages in top soils on trails and forest slopes were done and Table 5 shows the results obtained from various trails in BTNR.

Research shows that root distribution is greatly altered due to soil compaction (Shierlaw \& Alston, 1984). Compaction decreases root length in the soil. Where bulk density is $1550 \mathrm{~kg} \mathrm{~m}^{-3}$, root length in the compacted soil is about $50 \%$ of the maximum (Shierlaw \& Alston, 1984). Bukit Timah's trails show differences in root density versus soil compaction that are very similar to what was found by Shierlaw \& Alston (1984) (Table 5). At that high density, the penetrometer resistance of the soil is 1250 and $5000 \mathrm{kPa}$. Roots fail to grow completely through the compacted layer of soil 
Dry Bulk Density of Top Soil from all locations in BTNR (2014)

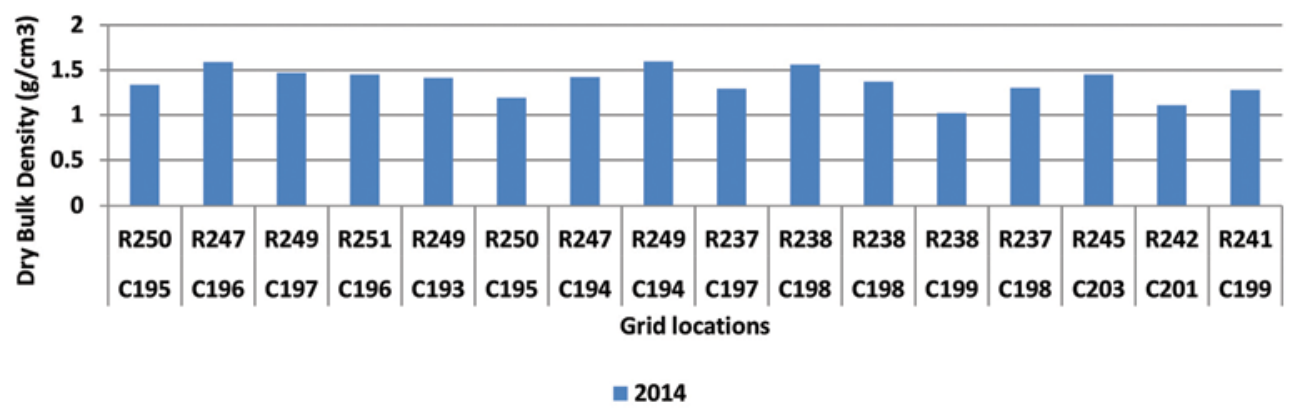

Fig. 7. Dry Bulk Density on locations along all trails in BTNR (2014).

Table 4. Dry bulk density changes with depth in Bukit Timah Nature Reserve, Singapore.

\begin{tabular}{llc}
\hline & Depth $(\mathbf{c m})$ & $\mathbf{g} / \mathbf{c m} \mathbf{3}$ \\
\hline Trail & $0-10$ & 1.40 \\
& $10-20$ & 3.33 \\
& $20-40$ & 2.19 \\
& $0-20$ & 1.20 \\
Lower Forested Slope & $20-40$ & 1.49 \\
& $0-10$ & 0.85 \\
Upper Forested Slope & $10-20$ & 0.78 \\
& $20-30$ & 1.32 \\
\hline
\end{tabular}

at bulk densities $\geq 1550 \mathrm{~kg} \mathrm{~m}^{-3}$. In BTNR, trail surface records show DBD as high as $3.33 \mathrm{~g} \mathrm{~cm}^{-3}\left(3330 \mathrm{~kg} \mathrm{~m}^{-3}\right)$. The inversely proportional relationship between DBD and root density is apparent when root densities are examined both from forest and trail soils. At BTNR such tests yielded results that clearly show that due to the extreme compacted conditions on the trails, the soils there do not allow roots of vegetation to expand. In the long run, this is detrimental to the health of the forest as such inhibited conditions will affect vegetation regeneration as long as trail surfaces remain as an impediment to root extension.

Quite consistently trail surfaces yielded much lower organic matter from the top soils, as compared to the forest soils. While the forest soils yielded $8.5-18.2 \%$ organic matter, the dry, severely compacted trail soils had only $4.6-5.8 \%$ organic matter, with 

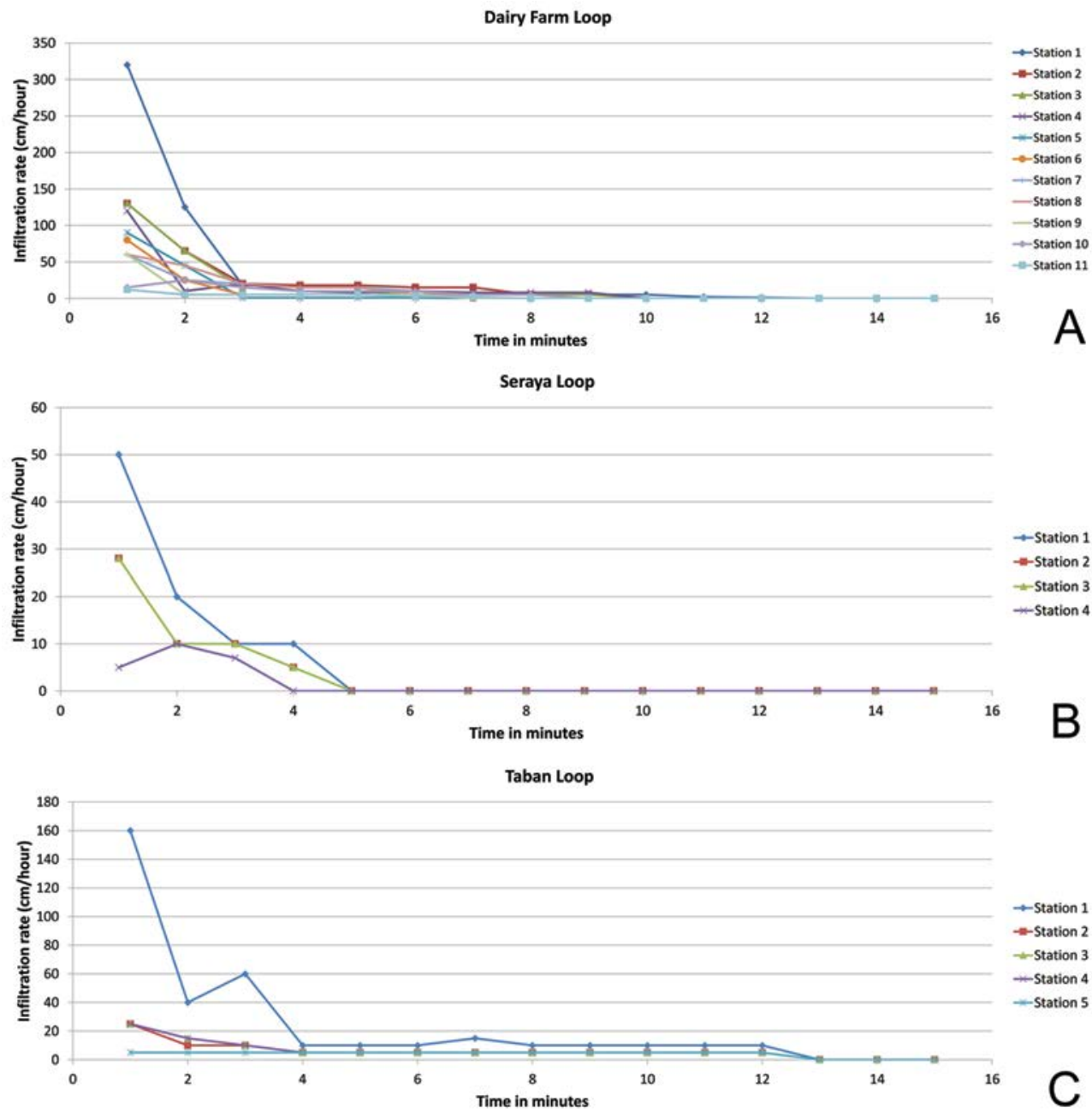

Fig. 8. Infiltration Rates recorded on various trails (Test duration: 15 mins duration). A. Seraya Loop. B. Dairy Farm Loop. C. Taban Loop.

a minimum of only $1.31 \%$. Therefore, it seems that the compacted trails do provide quite a hindrance to root growth and extension, as seen in the root density and soil organic matter content.

The overall forest environment during this period of heavy visitor arrivals was one of severely compacted and trampled trails which deteriorated over time.

\section{Forest management responses}

As trails became increasingly degraded, forest management engaged in several repair strategies, such as barriers along the sides of trails to prevent trailsides becoming incorporated into the trail (Fig. 10). 
Soil Organic Matter on Forest and Trail surfaces at BTNR (2005 and 2006):

Determined by LOI Method

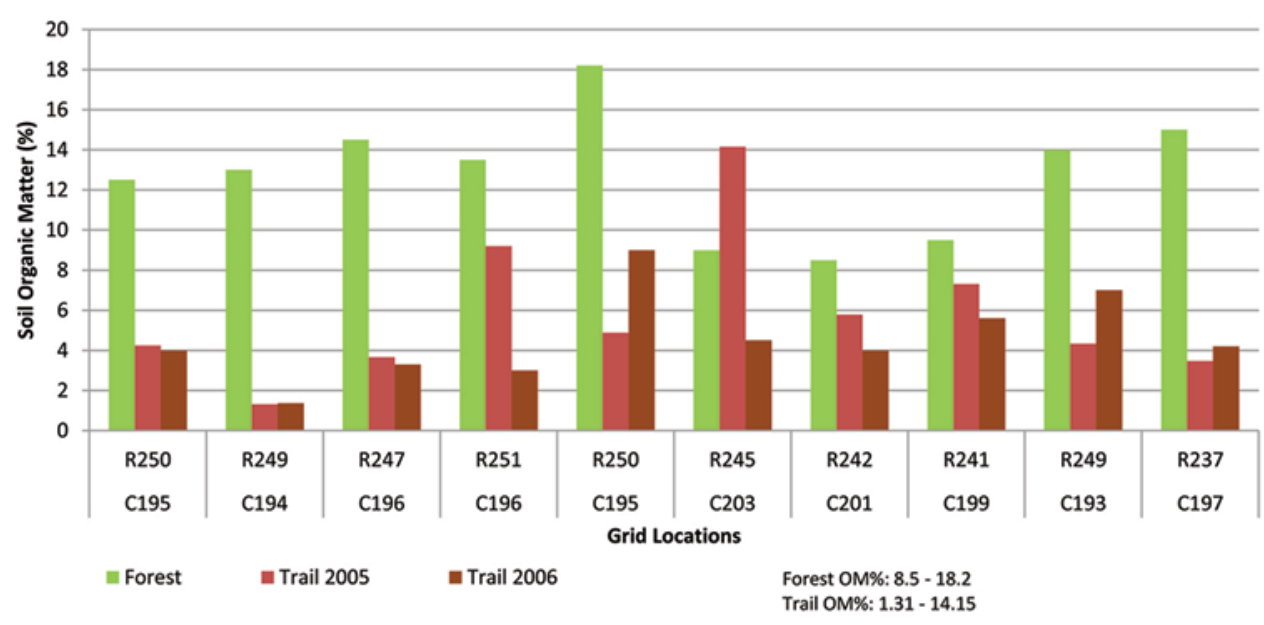

Fig. 9. Soil Organic Matter Percentages on Forest and Trail surfaces.

Before the official long forest closure, the steps taken to minimize trail widening included the installing of railings or laying of fallen logs on either side of the trails. Where trails became muddy, slabs of tree trunks were placed as stepping stones for visitors. The costs of trail maintenance varied depending on the weather, visitorship, and the type and extent of repair needed (S.K.L. Chan, pers. comm., 2004).

Repair work was usually carried out on ad-hoc basis, as a series of temporary measures. In 2015, however, work was due to begin on reconstruction of the visitor centre, a major infrastructure project. To prevent risks to members of the public, it was necessary to close access to the nature reserve for some time, particularly because the main access route was adjacent to the construction site, and the main car park was adjacent to movement of construction vehicles. The closure provided an opportunity, not just to repair the damaged segments of trails, but also to allow natural regeneration of the forest's physical as well as the biotic environment. The severely impacted trail conditions had developed over more than two decades of heavy usage and it was recognised that substantial work would be required to repair and reorganise the trails. The forest was closed to the public from 15 September 2014 for a period of two years, though certain limited access was given to the public from 1 April 2015. The forest was fully reopened to the public in October 2016. During this closure the National Parks Board took the opportunity to conduct repair and restoration works to the slopes, trails and the forest in the reserve. Slopes were stabilised, trails and forested areas were repaired and restored, and visitor amenities and infrastructure were upgraded. Badly impacted and failed slopes were repaired, as much as possible, using local material (wood from the forest). Some $5 \mathrm{~km}$ of trail surfaces were repaired, three slopes were stabilised, habitat enhancement was done through planned reforestation and enrichment planting, and some trails were realigned. 
Table 5. Variations in root densities in soils on trails and in the forest away from trails in Bukit Timah Nature Reserve, Singapore. Maximum and minimum values for the two categories are given in bold font.

\begin{tabular}{lll}
\hline & Root density (percentage mass per unit weight of dry soil) \\
& Trail & Forest \\
\hline Catchment Path & $\mathbf{0 . 0 1}$ & $\mathbf{0 . 3}$ \\
Tiup Tiup Path & 0.57 & 1.6 \\
& 0.30 & $\mathbf{4 . 1 3}$ \\
Kruing Path & 0.01 & 0.66 \\
& 0.02 & 0.78 \\
Rock Path & 0.01 & 0.84 \\
Northview Path & $\mathbf{2 . 9 3}$ & 3.65 \\
& 2.63 & 3.58 \\
Southview Path & 0.1 & 3.6 \\
Cave Path & 0.05 & 0.49 \\
Taban Loop & 1.7 & 0.56 \\
& 0.01 & 0.44 \\
& 0.11 & 1.32 \\
\hline On Trail & 1.34 & 1.32 \\
\hline In Forest & $0.01-2.93 \%$ (Mean 0.7\%) & \\
\hline
\end{tabular}

Figure 10 shows some of the trail amelioration carried out by the National Parks Board during the closure repair work. The strategies for the trail repairs aimed at reducing trampling impact on the trail surface by introducing boardwalks on steep sections, altered surface materials on impacted areas, reducing the scope for trail extension by establishing barriers on the sides and also providing dual-height steps, to discourage visitors from straying on the sides for easier access to slopes. Some difficult trails have been closed to visitors to help the trails regenerate naturally.

\section{The impact of the closure on forest physical conditions}

\section{Physical status of the forest after reopening}

During the period from September 2014, when all forest trails were closed to public access, the trail segments and the surface conditions were left mostly untouched, unless repair works were carried out in some sections. The Seraya Loop was 


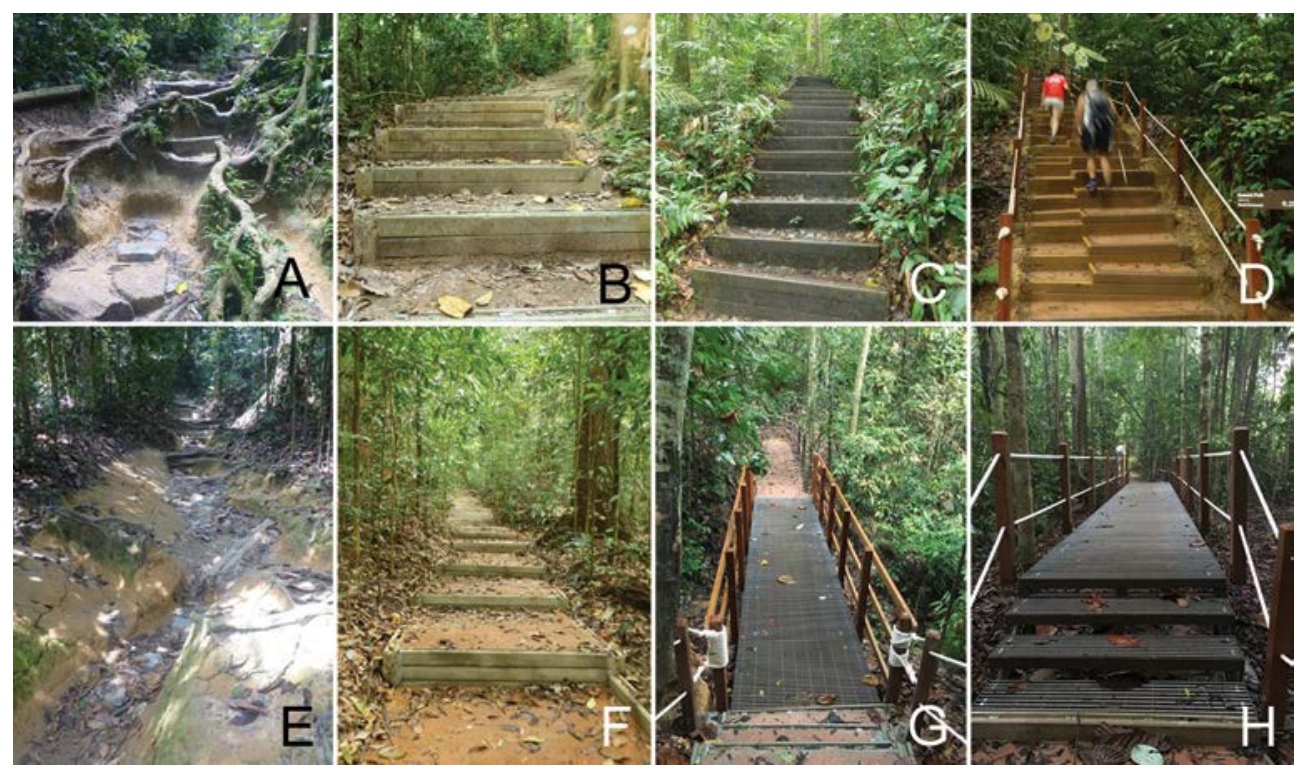

Fig. 10. Some of the trail repairs done by BTNR forest management during the forest closure. A. Dairy Farm Loop in January 2014. B. The same trail in July 2016 after repairs were made to control erosion. C. Summit Trail in Aug 2014. D. The same trail in Aug 2015, after enhancements were made to the steps. E. Catchment Path before repair in Febuary 2014. F. The same path in July 2016. G. Broadwalk were constructed at various areas to minimise visitor impact to muddy stretches. H. Another broadwalk at the Dairy Farm loop area. (Photos: C. Chia).

permanently closed to visitors, as was Tiup Tiup Path. During this period soil surface conditions as well as soil characteristics were measured to examine the impact of the closure and to assess the degree of regeneration, if any, of the forest physical conditions. The first measurements were taken between December 2015 and January 2016. This was to find out how the trails performed during the closure. Another measurement was carried out in March 2017, approximately 6 months after the forest was reopened for public access. The objective of both of these monitoring events was to establish the degree of regeneration of surface and soil conditions during the period of no use. The exercise is aimed at providing an insight on natural forest regeneration and it might serve as guidance for future management strategies for the forest. The same trails were monitored for surface penetration resistance (soil compaction), soil dry bulk density, soil organic matter and the values are compared with the previous observations, to examine the changes.

\section{Post-closure changes}

Observations were made on Seraya Loop (previously heavily impacted, but now closed to public), Dairy Farm Loop, Cave Path, Catchment Path, Taban Loop, Northview Path, Southview Path. Changes in Surface Penetration Resistance from 2004 to 2017 are seen in Figures 11, 12, and 13. 


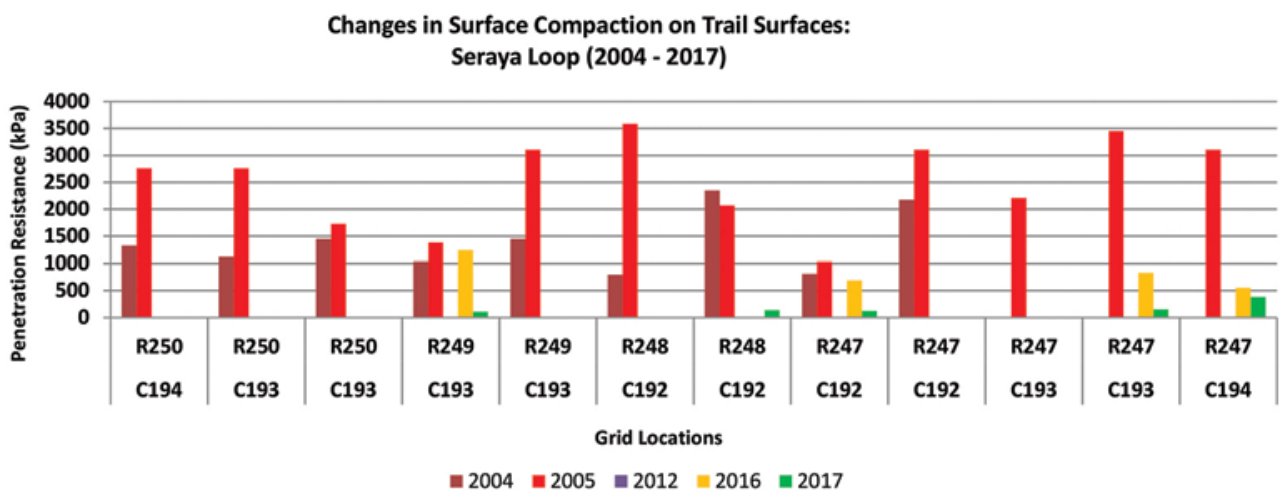

Fig. 11. Changes in Surface Compaction on Seraya Loop trail surface between 2004 and 2017.

Changes in Surface Compaction on Trail Surfaces:

Dairy Farm Loop (2005 - 2017)

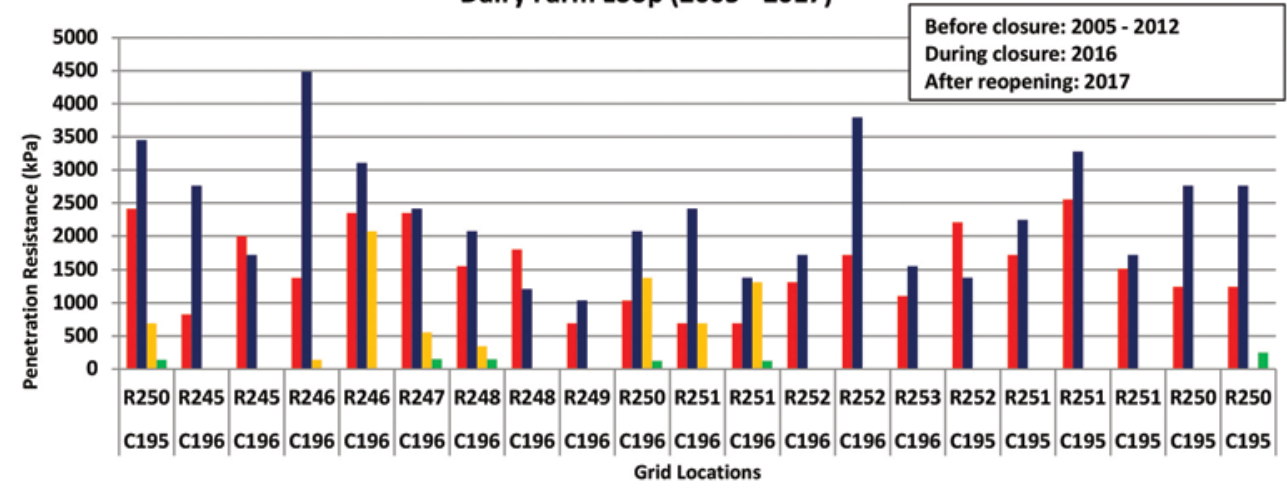

$=2005=2012=2016=2017$

Fig. 12. Changes in Surface Compaction on Dairy Farm Loop trail surface between 2005 and 2017.

Changes in Surface Compaction on Trail Surfaces:

Cave Path, Catchment Path, Taban Loop, Southview Path, Northview Path (2005 - 2017)

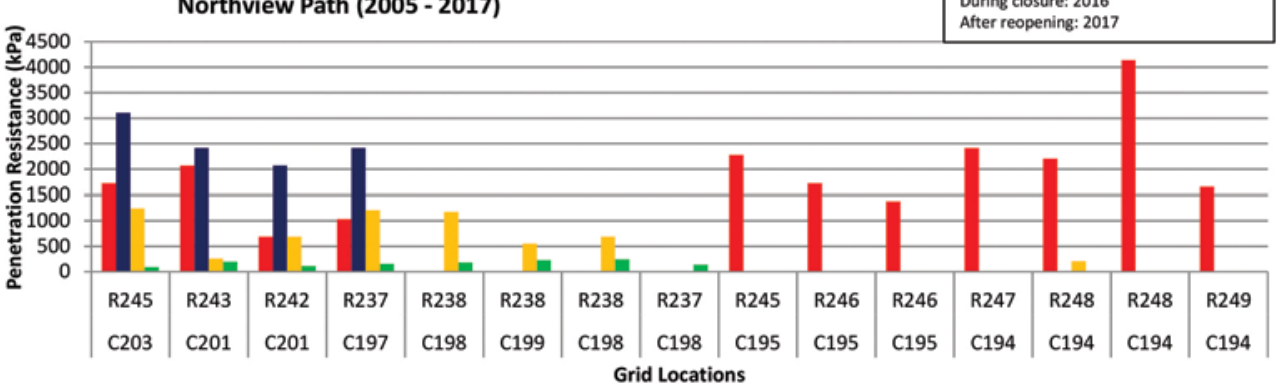

=2005 $=2012=2016=2017$

Fig. 13. Changes in Surface Compaction on all other trail surfaces between 2005 and 2017. 
Since the closure, the trail surface compaction has been reduced by several magnitudes. Figure 14 shows the surface hazard status before forest closure and Figure 15 shows the changes in the hazard status recorded at the end of the forest closure. Monitoring of the trail compaction status in the post-reopening stage revealed that all monitored sites were placed in the No Hazard status. Figure 15 demarcates the exact grid locations for this immense improvement of the forest trail surface condition, following the closure of the forest. The two sets of data indicate that after leaving the forest trails unused for about 16 months, there was natural regeneration of the soil conditions, without any active intervention or amelioration from the managers.

The soils along the trails also improved immensely in terms of their organic matter contact. Figure 16 shows improvements in organic matter content during the two phases of monitoring. Again, like the surface compaction monitoring, readings were taken from trails after about 16 months of closure and then again about 6 months after reopening. Both the readings are shown in Fig. 16. Every monitored site recorded increase in organic matter. This is expected as in the absence of trampling, the forest floor litter was allowed to settle down and get naturally degraded through bioactivity and, finally, get incorporated in the soil.

Along with increases in organic matter in top soils, there has also been some improvement in the dry bulk density of the soils (Fig. 17). This is also reflected in the compaction values.

\section{Conclusion: Altered physical status of the Bukit Timah Nature Reserve}

From the long-term monitoring studies it is evident that the forest interior conditions have degraded, spiraling downwards in synchrony with the increasing usage over the initial years of the nature reserve's popularity. The management intervention of the two-year closure brought some of the original forest conditions back on track, with natural regeneration of trail surfaces, soil conditions and soil bio-environments. This is heartening as it provides guidance towards future management strategies of the forest. While previous ad-hoc repairs and closures provided some ad-hoc results, a more concerted and uninterrupted repair, rehabilitation, and readjustment of interior infrastructure and environment seem to be the way to go forward in management of BTNR. Another outcome of the closure between 2014 and 2016 is the public awareness of the importance of such closures and also the public acceptance of such initiatives. The recent closure will be a useful precedent for future conservation efforts.

From longitudinal data spanning 13 years on BTNR's interior physical environment, it is evident that, during the period between 2004 and 2015, when the popularity of the forest as a nature refuge for the neighbouring urban residents peaked with more than 400,000 visitors in a year, BTNR transformed from an almost unknown forest to one that was extremely heavily visited. The primary problem of BTNR is its proximity to a huge resident population and its attraction as an indigenous, natural forested environment. With annual visitor numbers as high as 400,000, the $10.6 \mathrm{~km}$ walking trails alone saw a staggering 1103 visitors per day. This figure is the minimum 


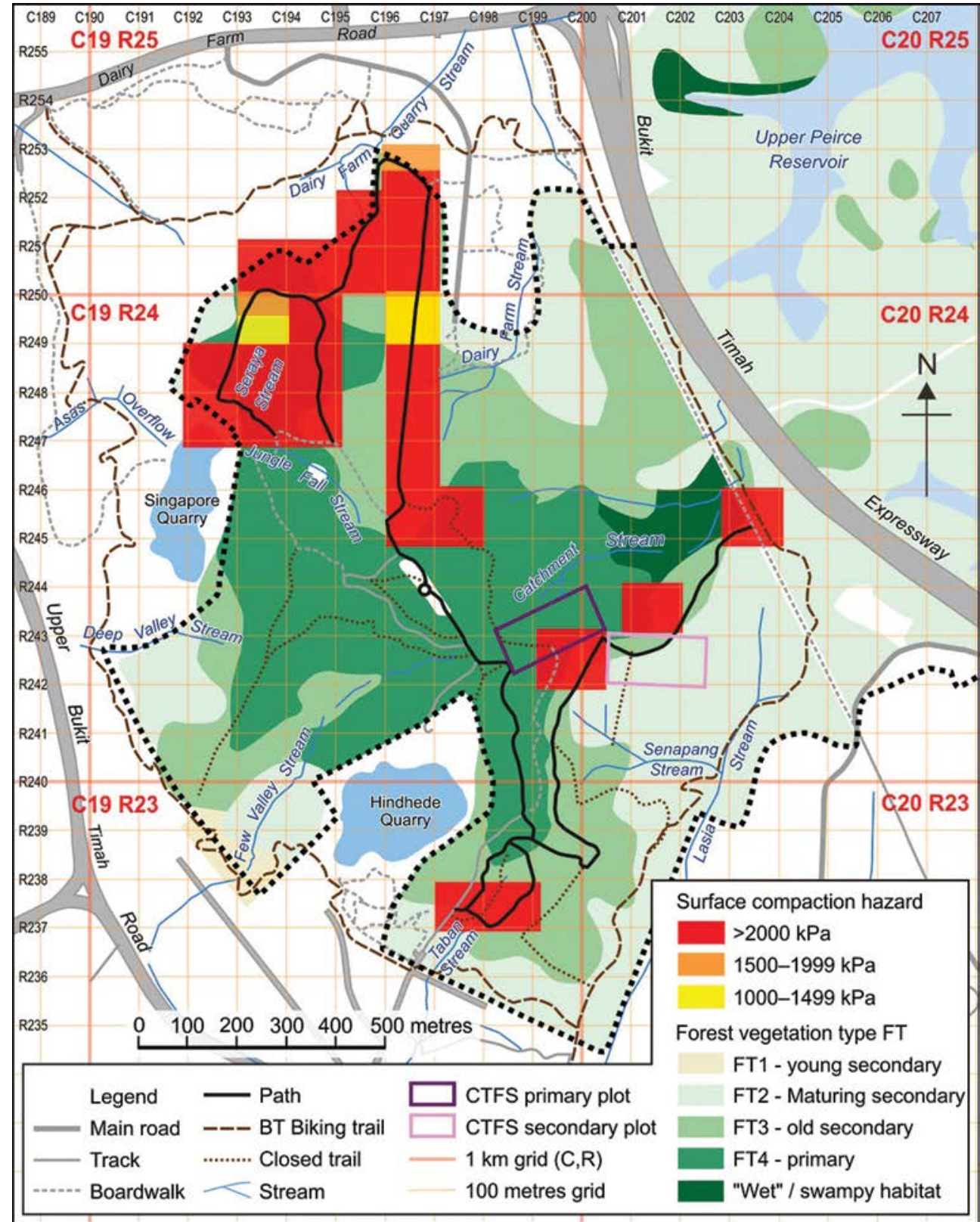

Fig. 14. Grid locations showing surface compaction zones before forest closure.

as visitors entering from the six unguarded entrances are not included in this data. As mentioned in Chatterjea (2012), if the IUCN guidelines of 10 persons per hectare per day for forest sustainability are followed, the 163 ha area of BTNR should be able to support a visitor number of only 1630 per day. Further, the 75 ha closed forested area 


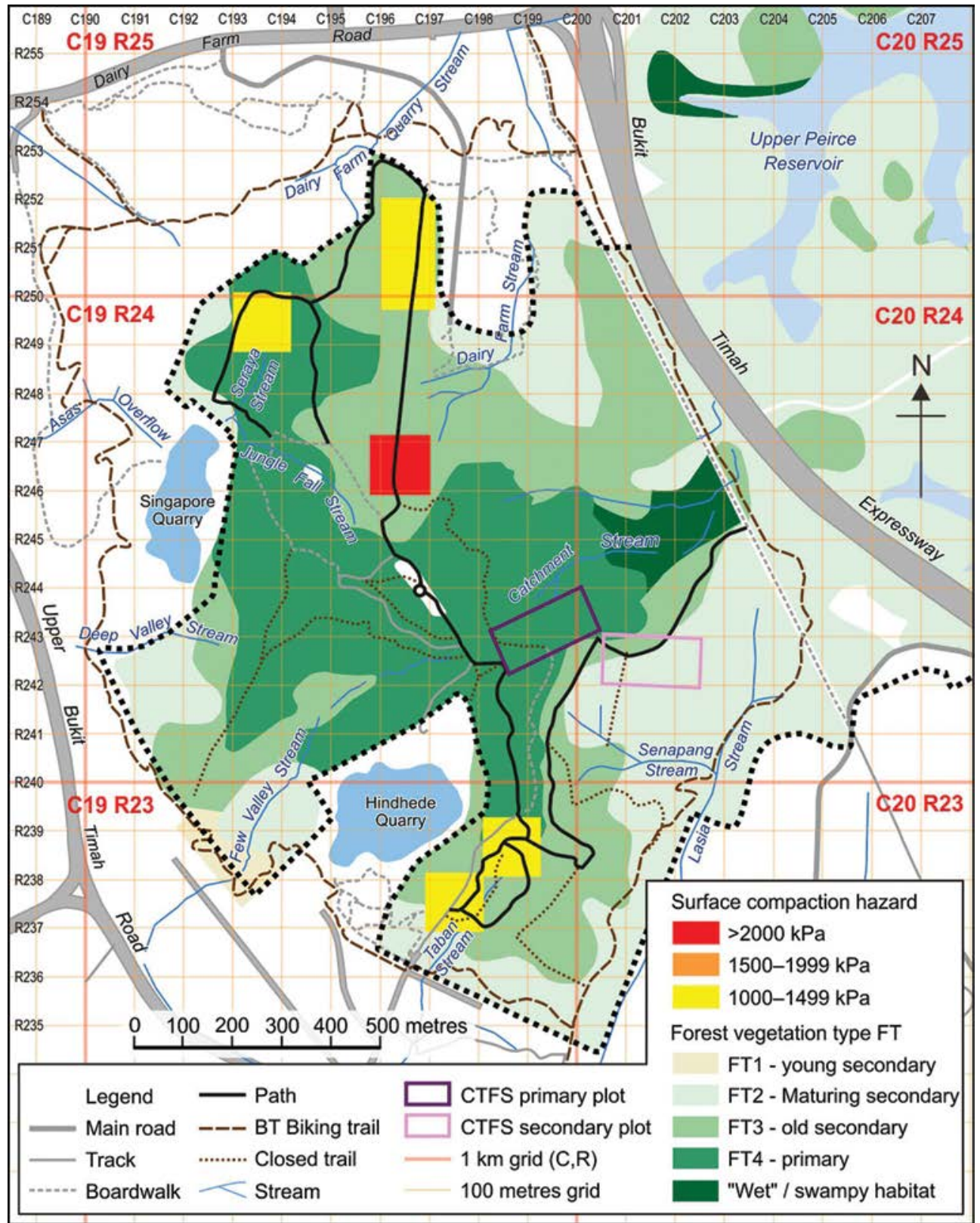

Fig. 15. Grid locations showing surface compaction zones at the end of forest closure.

of BTNR that is actually visited by people going to the trails can support an optimum visitor number of only 750 per day. If the present visitor preferences for the trails $(92 \%)$ are considered, the trails should only get a daily maximum of 690 visitors. The present figures (an estimated minimum of 1103 persons, not including the ones 


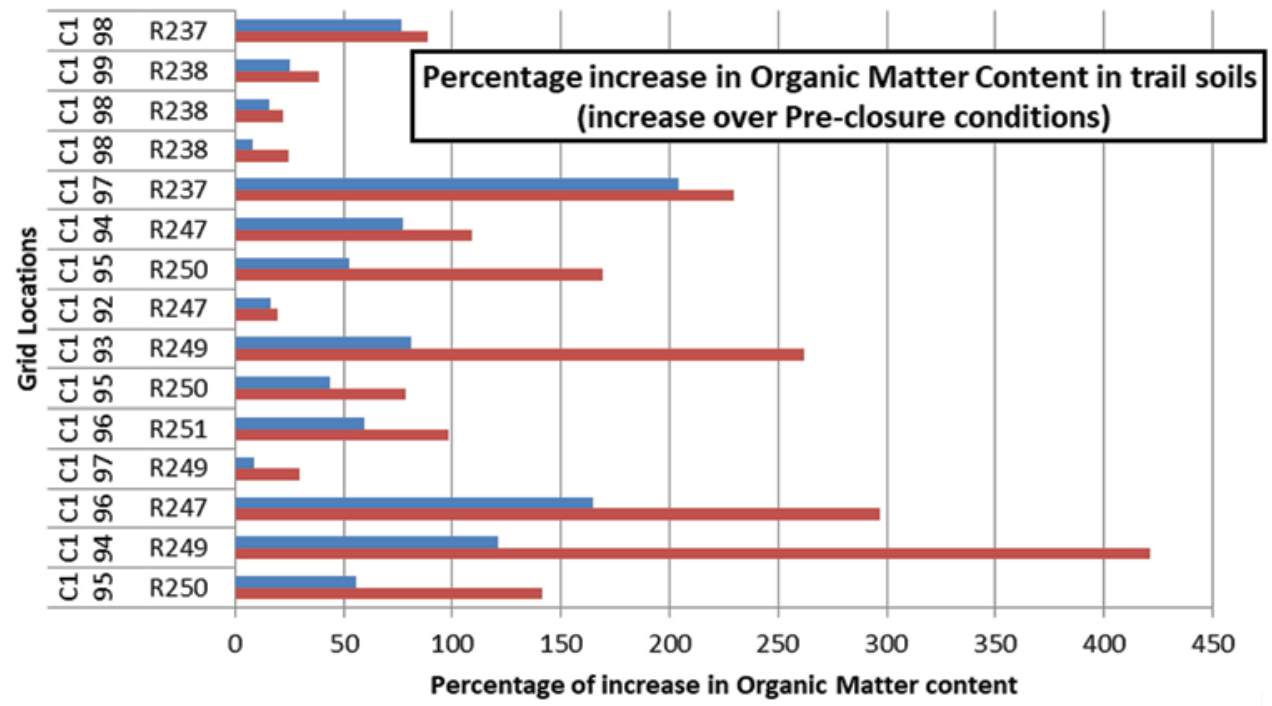

$2016 \square 2017$

Fig. 16. Percentage increase in Organic Matter in top soils of trails during closure and after re-opening.

\section{Comparison of Dry Bulk Density in Trail surface soils (Before Closure, During Closure and after Re-opening)}

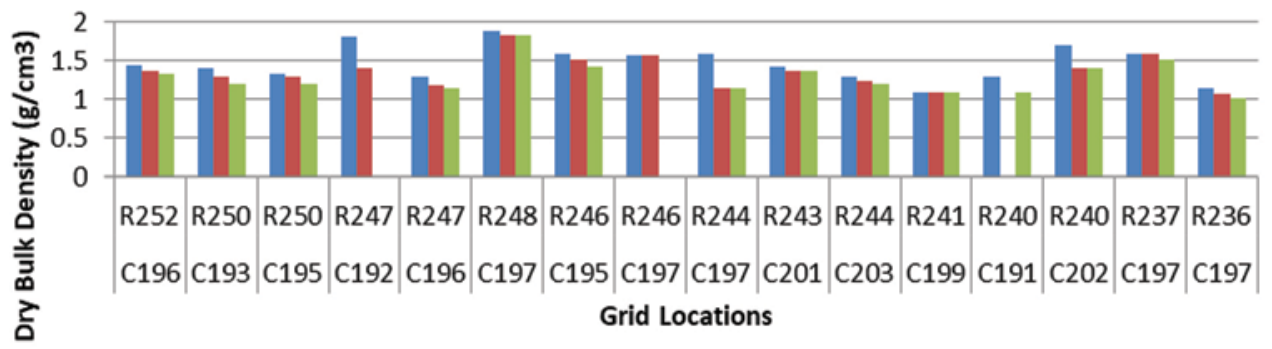

\section{$2015 \square 2016 \square 2017$}

Fig. 17. Changes in the Dry Bulk Density in trail surface soils following the forest closure.

who come to the forest through the unmanned entrances) are markedly higher than this optimum value. To respond to such increased preferences for the trails, the forest management initially expanded the length of trails to cater to the growing visitorship. But, later, when trails got heavily compacted and management became too difficult, in the 1992 upgrading programme, 8 trails were closed, still leaving more than 10.6 $\mathrm{km}$ of forest trails inside the main forest reserve boundaries, apart from the biking 
trails. This closure improved the trails and vegetation around Fern Valley, marked as a core area of the forest. During this period of gradual increase in popularity of BTNR, forest management involved regular checks of trails, ad-hoc measures for combatting extensions of trails by unruly users, partial closure of impacted trails, prevention of widening of trails by users, installation of logs as barriers at the verge of the trails, and the placement of logs to create by-passes in muddy areas.

While such measures were taken to reduce impact on the forest and also to provide a safe place for visitors, in-depth studies were a dire necessity to examine the actual site-specific conditions, to find a long term solution to the problem of huge visitorship, while also protecting the only primary rainforest reserve in Singapore. This longitudinal study aimed to do just that and the results reveal the transformation of the status of the forest as well as its journey from a little known forest of the 1980s and early 1990 s to the bustling recreational area of the 2000s.

The status of the forest has definitely changed over the years. The IUCN listing declares BTNR as a Category Ib forest (Wilderness Area: managed mainly for wilderness protection). According to this categorisation, 'Protected areas are usually large unmodified or slightly modified areas, retaining their natural character and influence, without permanent or significant human habitation, which are protected and managed so as to preserve their natural condition. The primary objective is to protect the long-term ecological integrity of natural areas that are undisturbed by significant human activity, free of modern infrastructure and where natural forces and processes predominate, so that current and future generations have the opportunity to experience such areas' (IUCN, 2017). But, with the changing trends of use of the forest, BTNR could well be placed in other categories such as Category II, a National Park, where along with the protection of natural biodiversity, the underlying ecological structure and supporting environmental processes, the area also promotes education and recreation. Alternatively, BTNR could be classed as Category IV (Habitat/Species Management Area), aiming to protect particular species and habitats with the management reflecting this priority. This category of protected areas needs regular, active interventions to address the requirements of particular species or to maintain habitats. Whatever category BTNR is classed as, it is increasingly evident that the forest cannot be protected as an isolated zone, away from public attention and use. That would not only alienate the forest from the public, but also reduce its status from a national Nature Area to one forgotten forest. The current strategy of redressing the impacts through direct and active intervention from time to time seems like the best option for continuing to protect Bukit Timah as the flagship Nature Reserve in Singapore.

ACKNOWLEDGEMENTS. This research was funded by NIE RP 19/02 KC and NIE AcRF Research Fund (RI 1/12KC). Many students of the National Institute of Education, Singapore assisted in gathering the huge amount of data over the years. Much collaborative assistance was given by Bukit Timah Forest Management (NParks Board). Many visitors also gave their responses which have been used in the analysis. 


\section{References}

Aanderud, Z.T., Bledsoe, C.S. \& Richards, J.H. (2003). Contributions of relative growth rate to root foraging by annual and perennial grasses from California oak woodlands. Oecol. 136: 424-430.

Bengough, A.G. \& Mullins, C.E. (1991). Penetrometer resistance, root penetration resistance and root elongation rate in two sandy loam soils. Institut National Agronomique Paris Grignon (France). Aberdeen Univ. (UK). Dept. of Plant and Soil Science.

Chan, L. \& Davison, G.W.H. (2019). Introduction to the Comprehensive Biodiversity Survey of Bukit Timah Nature Reserve, Singapore, 2014-2018. Gard. Bull. Singapore 71 (Suppl. 1): 3-17.

Chatterjea, K. (1989). Surface wash: the dominant geomorphic process in the surviving rain forest of Singapore. Singapore J. Trop. Geogr. 10(2): 95-109.

Chatterjea, K. (1994). Dynamics of Fluvial and Slope Processes in the changing geomorphic environment of Singapore. Earth Surf. Process. Landf. 19: 585-607.

Chatterjea, K (2006). Public use of urban forest in S E Asia, its impact, and related conservation issues: The Singapore experience. In: Wong, T.C., Goh, K.C. \& Shaw, B. (eds) Challenging Sustainability: Urban Development and Change in Southeast Asia, pp. 53-79. Singapore: Marshall Cavendish Academic.

Chatterjea, K. (2007). Assessment and demarcation of trail degradation in a nature reserve, using GIS: case of Bukit Timah Nature Reserve. Land Degrad. Dev. 18(5): 500-518.

Chatterjea, K. (2012). Sustainability of an urban forest: Bukit Timah Nature Reserve, Singapore. In: Diez, J. J. (ed.) Sustainable Forest Management, book 2, pp. 143-160. Rijeka: INTECH.

Chatterjea, K. (2014a). Impact of Urban Development on Singapore's Only Primary Rainforest. Int. J. Sci. Res. 3(7): 233-235.

Chatterjea, K. (2014b). Edge effects and exterior influences on Bukit Timah Forest, Singapore. Eur. J. Geogr. 5(1): 8-31.

Chatterjea, K. (2015). Dynamics of an Urban Forest in Response to Urban Development and Management Initiatives - Case of Bukit Timah Nature Reserve. In: Zlatic, M. (ed.) Precious Forests Precious Earth, pp. 51-82. Rijeka: INTECH.

IUCN (2017). Protected Area Categories. https://www.iucn.org/theme/protected-areas/about/ protected-areas-categories. Accessed 7 June 2017.

Moraes, M.T.D., Debiasi, H., Carlesso, R., Franchini, J.C. \& Silva, V.R.D. (2014). Critical limits of soil penetration resistance in a rhodic Eutrudox. Rev. Bras. Ciênc. Solo 38: 288-298.

Oei, G.L., Chatterjea, K., Chang, C.H. \& Lim, K.Y.T. (2007). Geographies of a Changing World: Global Issues in the Early 21st Century. Singapore: Prentice Hall.

Shierlaw, J. \& Alston, A.M. (1984). Effect of soil compaction on root growth and uptake of phosphorus. Plant Soil 77(1): 15-28.

Sinnett, D., Morgan, G., Williams, M. \& Hutchings, T. (2008). Soil penetration resistance and tree root development. Soil Use Manage. 24(3): 273-280. 